\title{
Dietas para frangos de corte contendo quirera de arroz
}

\author{
Performance of broiler feed with broken rice in diets
}

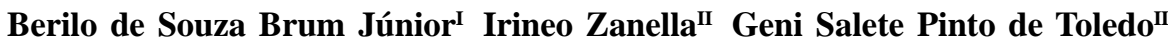 \\ Eduardo Gonçalves XavierIII Thiago Alves VieiraII Edílson Campos Gonçalves ${ }^{\text {II }}$ \\ Homero Brum ${ }^{\text {II }}$ Joyce Leite Siqueira de Oliveira ${ }^{\mathrm{IV}}$
}

\section{RESUMO}

\begin{abstract}
O experimento foi realizado para avaliar o uso da quirera de arroz na dieta de frangos de corte. Foram utilizados 240 pintos machos, alojados em galpão, contendo 12 boxes de $2 \mathrm{~m}^{2}$ de área. Cada box continha comedouro tubular, bebedouro pendular e campânula nos 21 dias iniciais. As aves foram distribuídas em um delineamento inteiramente casualizado, com três tratamentos e quatro repetições, as quais receberam dietas contendo 0, 20 e 40\% de inclusão de quirera de arroz. Os dados foram submetidos à análise de regressão $e$ à análise de variância e, quando houve diferença, aplicou-se o teste de Tukey. O ganho de peso, o consumo de ração e a conversão alimentar de 1-21, 1-35 e 1-42 dias $(P>0,05)$ não foram afetados pela substituição do milho por quirera de arroz. A umidade de cama, o índice de eficiência produtivo, o rendimento de carcaça quente, de fígado, coração, coxa, sobrecoxa e peito não apresentaram diferença $(P>0,05)$. No entanto, os rendimentos de moela, bem como a pigmentação da canela e do bico, diminuíram linearmente com o aumento do nível de quirera de arroz na dieta. Conclui-se que a quirera de arroz pode ser incluída nas dieta, substituindo o milho, para frangos de corte.
\end{abstract}

Palavras-chave: alimento alternativo, carcaça, desempenho.

\section{ABSTRACT}

An experiment was carried to evaluate the performance of broilers fed with diferent levels of broken rice. The experiment was conducted with 240 males broilers chicks, Cobb 500, were distributed in floor pens of $2 \mathrm{~m}^{2}$ each, with one tubular feeder, one pendular drinker, an electrical brooder and on the top of rice hulls. An entirely randomized experimental design was used, with 3 treatments and 4 replicates with 20 birds each, which received, diets containing 0,20 and $40 \%$ of broken rice. Data were submitted to Analisis of regression. Weight gain, feed intake, feed conversion to the1- 21, 1- 35 and 1-42 days of age, litter humidity, carcass, liver, breast, thigh and drumstick yield did not present significant difference. The gizzard and the carcass pigmentation decreased lineally with the increase of the level of broken rice in the diet. It is concluded with that the inclusion of up to $40 \%$ of broken rice in diet substituting the corn for broiler does not affect the performance, and carcass yield.

Key words: carcass, growth, feed ingredient.

\section{INTRODUÇÃO}

O avanço da nutrição exige cada vez mais dos nutricionistas a busca por alimentos com alta digestibilidade que sejam economicamente viáveis. A avaliação de alimentos alternativos e o uso destes na alimentação animal possibilitam a redução dos custos de produção, com reflexos diretos sobre a viabilidade do sistema produtivo avícola.

O arroz (Oryza sativa L.) é mundialmente produzido para ser consumido por humanos. Entretanto, quando não estiver dentro das especificações para o consumo humano ou quando razões econômicas o permitem, pode ser utilizado na

\footnotetext{
IPrograma de Pós-graduação em Zootecnia, Universidade Federal de Pelotas (UFPEL), Rua Dom Pedro II, 819, 96010300, Pelotas, RS, Brasil. E-mail: berilob@yahoo.com.br. Autor para correspondência.

IDepartamento de Zootecnia, Universidade Federal de Santa Maria (UFSM), Santa Maria, RS, Brasil.

IIIDepartamento de Zootecnia, UFPEL, Pelotas, RS, Brasil.

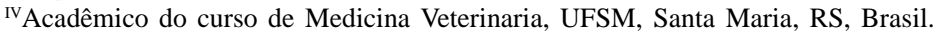


alimentação animal. A quirera de arroz é composta por grãos defeituosos e quebrados após o polimento, podendo ser utilizada na alimentação animal (TEIXEIRA, 1997). Essa pode ser encontrada em graus variados de limpeza e os principais contaminantes são cascas de arroz, sementes de capim-arroz (Equinocloa spp) e angiquinho (Aeschinomene spp).

A produção de arroz no mundo, em 2003, foi de 560 milhões de toneladas. O Brasil foi o nono maior produtor mundial e o primeiro da América Latina, com produção de 13.225.663 toneladas (IBGE, 2006). O Rio Grande do Sul participou com mais de 50\% deste número, tornando essa cultura uma de suas principais fontes econômicas (FAO, 2004; IRGA, 2004; IBGE, 2006).

O valor nutritivo de um alimento está diretamente relacionado com sua composição química, especialmente no que diz respeito ao conteúdo energético e protéico, importantes no balanceamento das rações. No Brasil, existe uma diversidade de alimentos que precisam ser mais bem avaliados, devido ao uso de diferentes processamentos (AZEVEDO, 1997). Esta variabilidade geralmente está relacionada à otimização econômica e ao atendimento dos requerimentos dos animais, sendo a principal barreira encontrada a variabilidade nos valores nutritivos que essas matérias-primas apresentam (FERREIRA, 1989).

Conforme ROSTAGNO et al. (2005), a quirera de arroz é um produto de alta qualidade que possui níveis protéicos e de energia metabolizável semelhantes aos do milho. Embora apresente um nível de gordura inferior ao do milho, a quirera de arroz compensa essa carência com o elevado teor de amido. Segundo o mesmo autor, o milho apresenta a energia bruta superior à da quirera de arroz, porém o nível de energia metabolizável aparente para aves é semelhante. Ainda comparada ao milho, a quirera de arroz apresenta um nível de fibra bruta inferior e de lisina e metionina levemente superiores, permitindo a formulação de dietas com menor nível de aminoácidos sintéticos, reduzindo assim o custo da ração. Porém, um ponto a ser ressaltado é o nível de triptofano mais elevado, pois, dependendo do produto com que será associado, a quirera poderá apresentar excesso desse nutriente, desencadeando a liberação de serotonina e inibindo o consumo de alimento. Porém, BUTOLO (2002) cita que de uma maneira geral a quirera de arroz é um ingrediente de baixa qualidade para frangos de corte, podendo ser utilizado em rações para poedeiras, suínos e bovinos de leite. Segundo o mesmo autor, para aves, deve-se utilizá-la em níveis mais elevados quando os alimentos forem peletizados, uma vez que a quirera de arroz contém níveis elevados de inibidores de tripsina, estruturas de baixo peso molecular que são destruídas pela temperatura e umidade durante o processo de peletização (termolábeis a $75 / 80^{\circ} \mathrm{C}$ ).

Com relação a fungos, TANAKA et al. (2001) dizem que seu desenvolvimento e a formação das aflatoxinas através de seus resíduos metabólicos nos alimentos são dependentes de uma série de fatores, entre eles a umidade, a temperatura, o oxigênio e o substrato. As aflatoxinas levam a degeneração gordurosa hepática e induzem diversas alterações, principalmente o aumento da atividade das enzimas, coagulopatias e diminuição na produção de proteínas (OLIVEIRA \& GERMANO, 1997). MARIN et al. (2002) sugerem que as aflatoxinas afetam não só o fígado dos monogástricos, mas também o intestino, os rins e o baço.

Segundo GHOSH et al. (1990), ocorre uma diminuição da síntese protéica pelo fígado e uma redução dos níveis séricos de albumina e globulinas nos frangos de corte quando alimentados com dietas contendo 30ppb de aflatoxinas. Uma das vantagens da utilização de quirera de arroz na dieta dos animais é a ausência ou o nível muito reduzido de micotoxinas devido à forma de colheita e processamento do arroz (BUTOLO, 2002).

Frente a isso, realizou-se um experimento com o objetivo de verificar a influência da inclusão de quirera de arroz na dieta, substituindo o milho, sobre o desempenho produtivo, as características de carcaça e a umidade de cama de frangos de corte de 1 a 42 dias de idade.

\section{MATERIAL E MÉTODOS}

O experimento foi realizado no Laboratório de Avicultura (LAVIC) do Departamento de Zootecnia da Universidade Federal de Santa Maria (RS), situado na região central do RS, a uma altitude de $149 \mathrm{~m}$, latitude sul 29 $42^{\prime}$ ' e longitude oeste $53^{\circ}$ 42' (ARAUJO, 1993), de primeiro de julho a 12 de agosto de 2004.

O galpão experimental de 15 x $10 \mathrm{~m}$ é coberto com telha de barro, com pé direito de $3 \mathrm{~m}$, laterais com mureta e tela de arame galvanizado e cortinas móveis para auxiliar no controle da temperatura interna do galpão. Cada box possuía $2 \mathrm{~m}^{2}$, sendo equipado com um comedouro semi-automático, com capacidade de $20 \mathrm{~kg}$, bebedouro pendular, cama de maravalha e campânula com lâmpada incandescente de $150 \mathrm{~W}$ até 21 dias de idade.

Foram utilizados 240 pintos machos da linhagem Cobb 500 com um dia de idade, provenientes

Ciência Rural, v.37, n.5, set-out, 2007. 
de matrizes com 42 semanas. Os animais foram distribuídos em um delineamento inteiramente casualizado entre os três tratamentos $(0,20$ e $40 \%$ de quirera de arroz), com quatro repetições cada. A quirera de arroz substituiu o milho, uma vez que os dois ingredientes apresentam composição nutricional semelhante (ROSTAGNO et al., 2000).

As aves receberam ração inicial (1 a 21 dias), crescimento (22 a 35 dias) e final (36 a 42 dias) conforme a tabela 1 e água à vontade.

A pesagem das aves e da ração foi realizada no $21^{\circ}, 35^{\circ}$ e $42^{\circ}$ dia, em balança digital. Para a obtenção do teor de umidade de cama, foi realizada uma préamostragem de três pontos da cama. A amostra foi colocada em estufa a $65^{\circ} \mathrm{C}$ com ventilação forçada, para se obter a amostra secada ao ar.

Para a avaliação da pigmentação da canela e do bico, foram retiradas quatro aves de cada box ao acaso, as quais foram avaliadas por quatro pessoas através de uma avaliação comparativa e subjetiva com o auxílio do leque colorimétrico de Roche.
A seleção das aves para o abate foi realizada através de pesagem dos frangos de cada box para o cálculo do peso médio. Após a obtenção do peso médio, foram retirados e anilhados duas aves com variação inferior a 5,0\% deste peso (2,5\% acima a 2,5\% abaixo), para o abate.

O custo de ração por quilograma de peso produzido foi calculado a partir do custo da ração multiplicado pela conversão alimentar do respectivo box. O índice de eficiência produtiva foi calculado a partir do ganho de peso e da viabilidade criatória.

$\mathrm{O}$ abate foi realizado quando as aves atingiram 42 dias de idade. Após o jejum de pré-abate (seis horas), as aves foram pesadas individualmente para o posterior cálculo do rendimento de carcaça quente, de fígado, de coração, de peito, de sobrecoxa e de coxa, em relação ao peso vivo. Para a realização do abate, primeiramente foi efetuado o atordoamento das aves com choque elétrico, seguido de sangria através de degola. Após a degola, as aves foram escaldadas em água a $75^{\circ} \mathrm{C}$ para posteriormente serem depenadas.

Tabela 1 - Composição centesimal e bromatológica de dietas para frangos de corte contendo 0, 20 e 40\% de quirera de arroz (QA). Santa Maria/RS (2005).

\begin{tabular}{|c|c|c|c|c|c|c|c|c|c|}
\hline \multirow{2}{*}{$\begin{array}{l}\text { Fases } \\
\text { Ingred. \% }\end{array}$} & \multicolumn{3}{|c|}{ Inicial (1-21 dias) } & \multicolumn{3}{|c|}{ Cresc (22-35 dias) } & \multicolumn{3}{|c|}{ Final (36-42 dias) } \\
\hline & QA0 & QA20 & QA40 & QA0 & QA20 & QA40 & QA0 & QA20 & QA40 \\
\hline Milho & 50,9 & 30,9 & 10,9 & 57,2 & 37,2 & 17,2 & 62,5 & 42,5 & 22,5 \\
\hline Farelo de Soja & 41,5 & 41,5 & 41,5 & 35,0 & 35,0 & 35,0 & 29,3 & 29,3 & 29,3 \\
\hline Quirera de Arroz & - & 20,0 & 40,0 & - & 20 & 40 & - & 20,0 & 40,0 \\
\hline Óleo de Soja & 3,74 & 3,74 & 3,74 & 4,13 & 4,13 & 4,13 & 4,63 & 4,63 & 4,63 \\
\hline F. Bicálcico & 1,73 & 1,73 & 1,73 & 1,60 & 1,60 & 1,60 & 1,47 & 1,47 & 1,47 \\
\hline Calcário & 1,10 & 1,10 & 1,10 & 1,10 & 1,10 & 1,10 & 1,10 & 1,10 & 1,10 \\
\hline Sal & 0,40 & 0,40 & 0,40 & 0,40 & 0,40 & 0,40 & 0,40 & 0,40 & 0,40 \\
\hline DL-Metionina & 0,17 & 0,17 & 0,17 & 0,14 & 0,14 & 0,14 & 0,10 & 0,10 & 0,10 \\
\hline L-Lisina & 0,05 & 0,05 & 0,05 & 0,04 & 0,04 & 0,04 & 0,03 & 0,03 & 0,03 \\
\hline L-Treonina & 0,15 & 0,15 & 0,15 & 0,12 & 0,12 & 0,12 & 0,09 & 0,09 & 0,09 \\
\hline Suplemento ${ }^{1}$ & 0,60 & 0,60 & 0,60 & 0,60 & 0,60 & 0,60 & 0,60 & 0,60 & 0,60 \\
\hline \multicolumn{10}{|c|}{ Composição quimica² } \\
\hline Umidade \% & 10,71 & 11,19 & 11,05 & 10,47 & 10,43 & 10,95 & 10,63 & 10,51 & 10,81 \\
\hline $\mathrm{EM}(\mathrm{Mcal} / \mathrm{kg})^{3}$ & 3,0 & 3,0 & 3,0 & 3,1 & 3,1 & 3,1 & 3,2 & 3,2 & 3,2 \\
\hline Proteína \% & 22,25 & 23,81 & 22,70 & 21,59 & 21,81 & 22,03 & 17,58 & 17,80 & 17,36 \\
\hline Cinzas \% & 6,55 & 5,29 & 5,82 & 5,37 & 5,48 & 4,53 & 4,90 & 5,07 & 4,63 \\
\hline E Etéreo \% & 7,36 & 5,54 & 5,73 & 7,11 & 6,88 & 5,83 & 7,17 & 7,18 & 5,49 \\
\hline Fibra Bruta \% & 2,72 & 3,02 & 2,20 & 3,07 & 2,65 & 4,63 & 3,12 & 2,49 & 2,30 \\
\hline Cálcio \% & 1,32 & 0,93 & 1,13 & 0,83 & 0,93 & 0,81 & 0,91 & 0,88 & 0,91 \\
\hline Fósforo Tot.\% & 0,82 & 0,63 & 0,68 & 0,60 & 0,62 & 0,57 & 0,53 & 0,58 & 0,51 \\
\hline
\end{tabular}

${ }^{1}$ Suplemento Vitamínico-Mineral: quantidade por kg de ração: vit A(UI)12.000; Vit D3 (UI)4.500; Vit E (mg) 24; Vit K3 (mg) 3; Vit B1

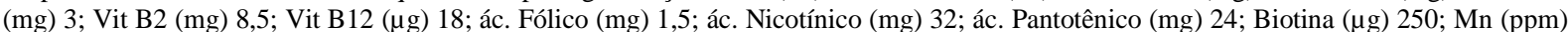
90; Zn (ppm) 80; Fe (ppm) 60; Cu (ppm) 12; I (ppb) 900; Se (ppb) 300; Salinomicina (ppm) 60; Bacitracina de zinco (ppm) 60; Olaquindox (mg) 50; endox (ppm) 80.

${ }^{2}$ Análises realizadas pela VITAGRI - Apucarana-PR (2004).

${ }^{3}$ Composição calculada. 
A evisceração e os cortes foram feitos manualmente e pesados para posterior cálculo do rendimento dos mesmos.

Os dados foram submetidos à análise de regressão e à análise de variância com o auxílio do pacote estatístico SAS (1996) e, quando houve diferença significativa, as médias foram submetidas ao teste de Tukey a 5\% de significância.

\section{RESULTADOS E DISCUSSÃO}

Os dados de desempenho produtivo estão representados na tabela 2 . O ganho de peso e o consumo de ração de 1-21, 1-35 e 1-42 dias não foram afetados $(\mathrm{P}>0,05)$ pela inclusão de quirera de arroz na dieta das aves. Segundo CONCI et al. (1996), a quirera de arroz é um excelente ingrediente para rações. Quando seu preço é inferior ao do milho, pode substituí-lo, sendo $10 \%$ a proporção mais usual, porque a disponibilidade é geralmente pequena e sazonal. No presente estudo, entretanto, a quirera de arroz foi incluída em até $40 \%$ e não foi observada diferença significativa quanto ao desempenho das aves.

O nível de quirera de arroz na dieta não influenciou a conversão alimentar nas diferentes fases, a umidade de cama aos 42 dias e o índice de eficiência produtivo $(\mathrm{P}>0,05)$ (Tabela 2$)$, embora as variáves avaliadas tenham sido melhores que os dados obtidos a campo com animais da mesma linhagem. Entretanto, RAMA RAO et al. (2001) observaram uma redução na eficiência alimentar e no peso dos ovos de matrizes alimentadas com quirera de arroz.
Os dados de carcaça estão representados na tabela 3. A quirera de arroz não afetou o rendimento de carcaça quente, de fígado, de coração, de peito, de sobrecoxa e de coxa.

O rendimento de moela diminuiu linearmente com o aumento do nível de quirera de arroz (Figura 1). Isso pode ter ocorrido em função da maior degradabilidade do arroz, por possuir menor nível de fibra e maior nível de amido, conforme ROSTAGNO et al. (2000) e ROSTAGNO et al. (2005). Esses resultados vão de encontro aos citados por BUTOLO (2002), que cita a quirera de arroz como um produto de baixa qualidade para frangos de corte, sendo mais usada para poedeiras e preferencialmente em dietas peletizadas por conter altos níveis de inibidores de tripsina, que são destruídos pelo calor durante o processo de peletização. Conforme o mesmo autor, os níveis de proteína variam de 6,5 a 8,5 \% e a sua energia está ao redor de 2,7 Mcal de energia metabolizável por kg. Apesar disso, os dados de ROSTAGNO et al. (2005) para a quirera de arroz apresentam um nível protéico de $8,47 \%$ e energia metabolizável aparente para aves de 3,315 Mcal kg-1.

A pigmentação da canela e do bico diminuiu linearmente com o aumento do nível de quirera de arroz (Figura 2), comprovando a carência de pigmentos existentes no arroz quando comparado ao milho. Porém, apesar de apresentar carência de carotenóides, precursores de vitamina $A$, os frangos não apresentaram sintomas de carência, pois a vitamina fornecida via suplemento vitamínico foi suficiente para atender às necessidades das aves.

Segundo QUADROS et al. (2000), a substituição total do milho por quirera de arroz na dieta

Tabela 2 - Ganho de peso (GP), consumo de ração (CR) e conversão alimentar (CA) de 1-21, 1-35 e 1-42 dias, umidade de cama (U), índice de eficiência produtiva (IEP) de frangos de corte alimentados com níveis de quirera de arroz (QA) na dieta. Santa Maria/RS (2005).

\begin{tabular}{|c|c|c|c|c|c|}
\hline Variável & 0\%QA & $20 \% Q A$ & $40 \% \mathrm{QA}$ & $\mathrm{P}$ & $\mathrm{CV} \%$ \\
\hline GP21(g) & 849,9 & 870,3 & 894,3 & 0,637 & 7,04 \\
\hline GP35(g) & 1919,0 & 2096,0 & 2125,0 & 0,280 & 4,64 \\
\hline GP42(g) & 2562,0 & 2755,0 & 2742,0 & 0,350 & 3,60 \\
\hline CR21(g) & 1256,8 & 1224,6 & 1248,9 & 0,153 & 1,76 \\
\hline CR35(g) & 3275,2 & 3299,9 & 3294,8 & 0,947 & 3,39 \\
\hline CR42(g) & 4468,0 & 4572,6 & 4512,1 & 0,669 & 3,58 \\
\hline CA-1-21 & 1,49 & 1,41 & 1,40 & 0,489 & 7,41 \\
\hline CA-1-35 & 1,72 & 1,57 & 1,55 & 0,203 & 8,03 \\
\hline CA-1-42 & 1,75 & 1,66 & 1,65 & 0,405 & 6,73 \\
\hline U\% & 47,6 & 49,3 & 42,0 & 0,293 & 14,00 \\
\hline IEP & 347,8 & 347,0 & 353,8 & 0,939 & 8,43 \\
\hline
\end{tabular}

Tukey $(\mathrm{P}>0,05)$. 
Tabela 3 - Rendimento de carcaça quente (RCQ), fígado (RFI), coração (RCO), peito (RP) e sobrecoxa (RSC) e de coxa (RCX) de frangos de corte alimentados com níveis de quirera de arroz (QA) na dieta. Santa Maria/RS (2005).

\begin{tabular}{|c|c|c|c|c|c|}
\hline Variável & 0\%QA & $20 \% \mathrm{QA}$ & $40 \% \mathrm{QA}$ & $\mathrm{P}$ & CV \% \\
\hline RCQ \% & 81,24 & 80,76 & 81,68 & 0,482 & 1,666 \\
\hline RFI \% & 1,97 & 1,95 & 1,99 & 0,927 & 9,907 \\
\hline RCO \% & 0,61 & 0,64 & 0,56 & 0,070 & 10,58 \\
\hline RP \% & 24,46 & 26,28 & 24,99 & 0,082 & 6,32 \\
\hline RSC \% & 5,96 & 5,82 & 5,97 & 0,637 & 5,678 \\
\hline RCX \% & 5,01 & 4,76 & 4,93 & 0,194 & 5,587 \\
\hline
\end{tabular}

Tukey $(\mathrm{P}>0,05)$.

de suínos machos castrados nas fases de crescimento e terminação diminui o consumo de ração e não afeta o peso final, o ganho médio de peso e a conversão alimentar. Conforme APOLÔNIO et al. (2003), ao avaliarem a digestibilidade ideal da quirera de arroz, sorgo baixo tanino, farelo de trigo, milheto, leveduras de cana e de cerveja em suínos, somente a quirera de arroz e a levedura de cerveja apresentaram valores de digestibilidade aparente da proteína bruta acima de $80 \%$. Conforme esses mesmos autores, o coeficiente médio de digestibilidade aparente dos aminoácidos essenciais da quirera de arroz foi de $81 \%$. Entre os alimentos avaliados, a quirera de arroz foi o que apresentou os maiores coeficientes de digestibilidade para arginina e a isoleucina.

A inclusão de quirera de arroz na dieta de matrizes de corte não influi na produção de ovos e na fertilidade (RAMA RAO et al., 2001). Segundo o mesmo autor, o uso de quirera de arroz reduz a eficiência alimentar, o peso dos ovos e a coloração da gema, além de aumentar a gordura abdominal das aves.

Dietas extrusadas para cães à base de arroz possuem melhor digestibilidade, tornando o produto uma excelente fonte de energia. (KENDALL et al., 1982). Trabalhando com cães, SILVAJr., (2005) encontrou uma maior digestibilidade da matéria seca e do amido total em dietas com quirera de arroz quando comparadas às que continham milho, sorgo e mistura (milho + sorgo + arroz). Conforme esse mesmo autor, a quirera de arroz apresenta energia digestível igual à do milho e superior as demais.

\section{CONCLUSÕES}

A inclusão de quirera de arroz em até $40 \%$ na dieta de frangos de corte não interfere no desempenho destes, tornando-se necessária a inclusão

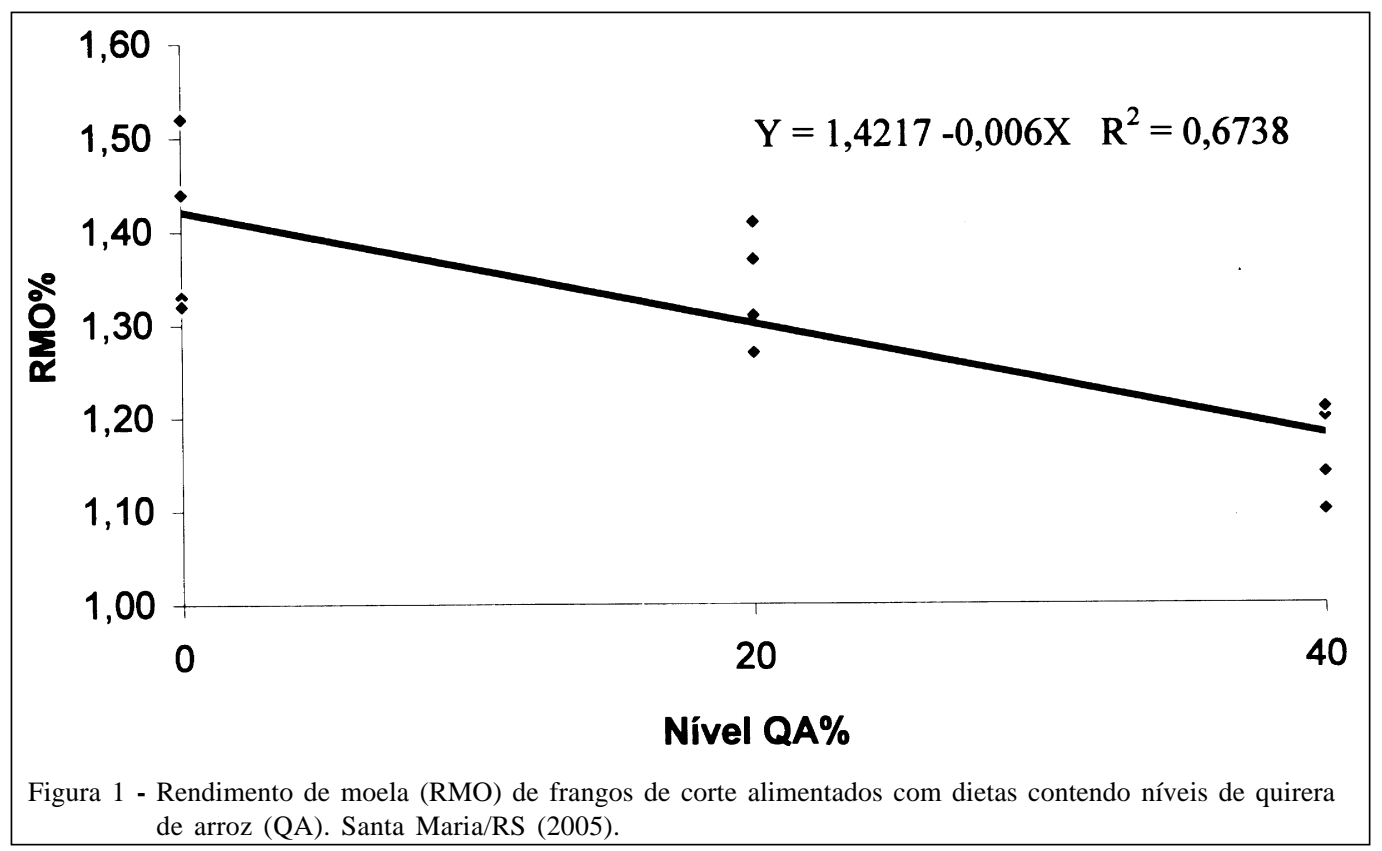

Ciência Rural, v.37, n.5, set-out, 2007. 


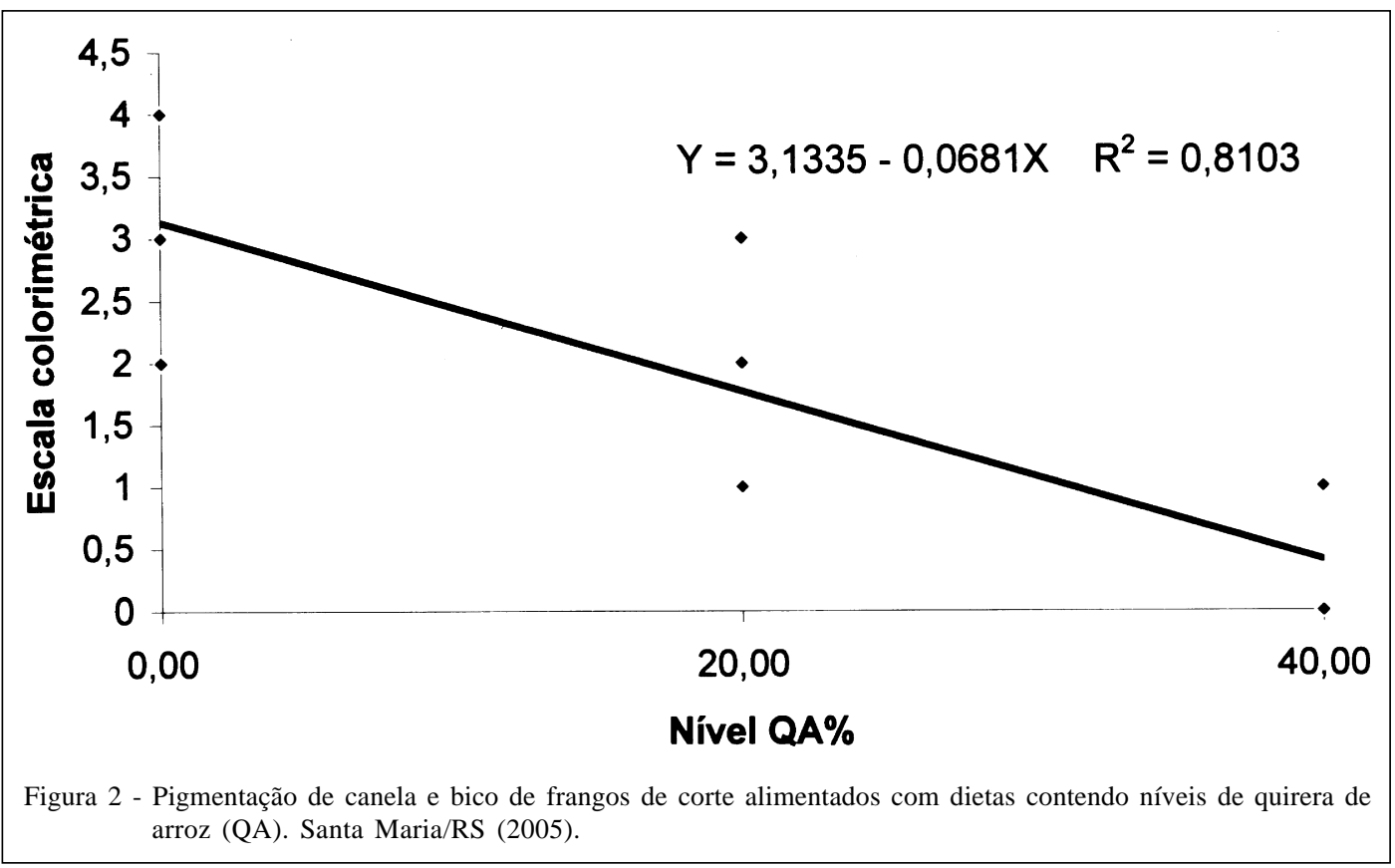

de pigmentante, quando se desejar uma carcaça mais pigmentada.

\section{REFERÊNCIAS}

APOLÔNIO, L.R. et al. Digestibilidade ileal de aminoácidos de alguns alimentos, determinada pela técnica da cânula t simples com suínos. Revista Brasileira Zootecnia, v.32, n.3, p.605614, 2003.

ARAÚJO L.C. Memória sobre o clima do Rio Grande do Sul. Rio de Janeiro: Diretoria de Meteorologia, Serv. Informe Agropecuário, 1993. 101p.

AZEVEDO, D.M.S. Fatores que influenciam os valores de energia metabolizável da farinha de carne e ossos para aves. 1997. 58f. Dissertação (Mestrado em Zootecnia) - Universidade Federal de Viçosa.

BUTOLO, J.E. Qualidade de ingredientes na alimentação animal. Botucatu/ SP: Faculdade de Medicina Veterinária e Zootecnia - UNESP, 2002. 430p.

CONCI, V.A. et al. Avaliação de subprodutos do arroz na alimentação de suínos. A quirera de arroz nas fases de recria e terminação. Pesquisa Agropecuária, v.14, n.159, p.49-53, 1996.

FERREIRA, W.M. Matérias-primas utilizadas na formulação de rações para coelhos:Restrições e alternativas. Informe Agropecuário, v.14 n.159, p.16-22, 1989.

FOOD AND AGRICULTURE ORGANIZATION OF THE UNITED NATIONS. FAO. FAOSTAT Database. Acesso em: 10 jul. 2004. On line. Disponível em: <http:// faostat.fao.org $>$.
GHOSH, R.C. et al. Immunosupression in broiler under experimental aflatoxicosis. British Veterinary Journal, v.146, p.457-462, 1990.

IBGE, Intituto Brasileiro de Geografia e Estatística,2004. Levantamento sistemático da produção agrícola. Acesso em: 25 set. 2006. On line. Disponível em: <http://www.ibge.gov.br/>.

IRGA, Instituto Riograndense do Arroz. Dados de safra. Acesso em: 07 jul. 2004. On line. Disponível em: <http:// www.irga.rs.gov.br/dados.htm>.

KENDALL, P. T. et. al. Comparative evaluation of net digestive and absorptive efficiency in dog and cats fed a cariety of contrasting diets types. Journal of Small Animal Practice, v.23, n.9, p.577-587, 1982.

MARIN, D.E. et al Changes in performance, blood parameters, humoral and cellular immune responses in weanling piglets exposed to low doses of aflatoxin. Journal of Animal Science, v.80, n.5, p.1250-1257, 2002.

OLIVEIRA, C.; GERMANO, P. Aflatoxinas: conceitos sobre mecanismos de toxicidade e seu envolvimento na etiologia do câncer hepático celular. Revista Saúde Pública, v.31, n.4, p.417-424, 1997.

QUADROS, A.R.B. de et al. Diferentes níveis de quirera de arroz usada em substituição ao milho na dieta suínos machos castrados - fase de crescimento / terminação. In: REUNIÃO ANUAL DA SBZ, 2000, Viçosa, MG. Anais... Viçosa: SBZ, 2000. CD-Rom.

RAMA RAO, S.V. et al. Effect of supplementary choline on the performance of broiler breeders fed on different energy sources. Br Poult Sci, v.42, n.3, p.362-367, 2001.

ROStagno, H.S. et al. Composição de alimentos e 
exigências nutricionais de aves e suínos. Tabelas Brasileiras. Viçosa: Universitárias, 2000. 142p.

ROSTAGNO, H.S. et al. Composição de alimentos e exigências nutricionais de aves e suínos. Tabelas Brasileiras 2.ed. Viçosa: UFV, 2005. 186p.

SAS. Statstical analysis system. User's guide: stat, Version 6.11 ed. Cary, 1996. 842p.
SILVA Jr., J.W. da et al. Digestibilidade de dietas com diferentes fontes de carboidratos e sua influência na glicemia e insulinemia de cães. Ciência agrotécnia, v.29, n.2, p.436-443, 2005

TANAKA, M.A.S. et al. Microflora fúngica de sementes de milho em ambientes de armazenamento. Science Agriculture. v.58, n.3, p.501-508, 2001.

TEIXEIRA, A.S. Alimentos e alimentação dos animais. 4.ed. Lavras: UFLA/FAEPE, 1997. 402p. 